\title{
Moral Rights Laws and Income Disparity Between Artists in High and Low GDP States
}

\author{
Victoria Avanesov ${ }^{1}$ and Robert Hodgson ${ }^{1 \#}$ \\ ${ }^{1}$ McDowell High School, Erie, PA, USA \\ "Advisor
}

$\underline{\text { ABSTRACT }}$

The United States' laissez-faire approach to moral rights legislation has left many academics questioning the impact that these laws have on artists' welfare. In using artists' income as one component of measuring overall wellbeing, states with additional statewide moral rights legislation have been shown to contribute to more significant artist losses, in contrast to states with only federal legislation. At the same time, moral rights laws have been shown to have no impact on artists' choice of residency, leaving some artists possibly disadvantaged regarding their choice of residency. Utilizing a difference in differences framework, this paper explores the impact of moral rights legislation on artists' weekly incomes between moral rights states of varying outputs of GDP. Although results suggested that artists would lose approximately $\$ 0.18$ per one billion dollar increase in GDP at the statewide level, after conducting an additional t-test, these findings were shown to have no statistical significance. Several limitations, most prominently a lack of data availability in the pre-law values required for the difference in differences framework, may have contributed to these findings. These indeterminate results leave the question of whether some artists remain economically disadvantaged as a result of moral rights legislation uncertain.

\section{Introduction: Origins of Moral Rights}

The term moral rights, deriving from the French phrase droit moral, was established from the philosophical idea that an individual artist's body of work is imbued with part of their spirit and personality. This concept catalyzed the idea that art should be protected and preserved in a manner different from traditional economic rights (Hansmann, H., \& Santilli, M., 1997; Landes, W. M., 2001; Lerner, R. E., \& Bresler, J. 2006). There are two schools of thought that deal with the intermingling, or lack-there-of, between economic and moral rights. The monist perspective was favored in Germany, and it championed the idea that economic and moral rights to a body of work should exist inseparably ${ }^{1}$. In contrast, the French dualist perspective followed the introduction of liberating ideals that prevailed following the French Revolution. This viewpoint called for the distinct separation of economic and moral rights (Lerner \& Bresler, 2006).

The French dualist perspective ultimately prevailed in establishing moral rights within the most widely respected international copyright treaty in the world, known as the Berne Convention (Lerner \& Bresler, 2006). Codified under article 6bis of the text, only two of the french moral rights became the minimum prerequisites for a countries' entrance into Berne, those being the rights to authorship and integrity. Authorship includes the right to have an artist's name associated with a particular body of work. At the same time, integrity deals with the artist's right to prevent their work from being presented in an altered, distorted, or mutilated form. The two other rights that were not incorporated into the treaty at Berne included the rights to disclosure and withdrawal. Disclosure refers to the right of refusal in sharing work with the public, while withdrawal relates to the artist's right to retract their work from a stream of commerce even after the work has left their hands (Berne Convention, 1971). These rights typically go unexercised

\footnotetext{
${ }^{1}$ Without the ability to be transferred or waived.
} 
in countries in which they are implemented. The process of exercising these rights involves removing the art from a stream of commerce, a process that can be incredibly costly for an artist. Therefore, these rights were not seen as compulsory for a country's entrance into Berne (Symposium, Authors, Attribution and Integrity, 2016).

The United States joined Berne relatively late compared to its international counterparts, qualifying under its compliance to the minimal attribution and integrity rights under common law. The US, ever since its juncture into Berne in 1988, has been notorious for its laissez-faire approach to the doctrine described in Berne (Lerner \& Bresler, 2006), passing its only piece of federal legislation dealing with moral rights shortly after- the Visual Artists Rights Act of 1990 (VARA). In comparing the scope of VARA to that of Berne, several important distinctions should be made. While Berne mandates protection for all works of art, including but not limited to photographic, cinematic, and visual arts, VARA only covers a work if it is both a work of visual $\operatorname{art}^{2}$ as well as a work of recognized stature ${ }^{3}$. In addition, the provisions under VARA last a shorter period than under Berne. One final key distinction between the two bodies of legislation is that, while waiver provisions and transferability of moral rights are not explicitly addressed under Berne, they are strictly prohibited under VARA (Berne Convention, 1971; Visual Artists Rights Act, 1990). In this regard, by limiting the transferability and waivabilty of these moral rights, the US adheres more closely to the monist point of view, causing an inconsistency between the US and the European Community in terms of perspectives.

Before the United States joined the Berne Convention in 1989, several individual states enacted their own, marginally disparate, variations of moral rights laws (Lerner, R. E., \& Bresler, J. 2006). Despite the Supremacy Clause of the Constitution granting supreme authority to federal over state law, under the proper circumstances, state laws may coexist with similar federal laws in the area of copyrights (Kewanee Oil Company v. Bicron Corporation, 1973). For instance, in the fictional example provided by Sirota (1992), a New York artist would not be entitled to the protections under VARA if they had greater than 200 copies of a limited work that they wished to protect. Even so, that same artist would be protected under New York's moral rights legislation, which protects "limited edition multiples of not more than three hundred copies by that artist". In essence, state laws dealing with moral rights, or any similar rights should not be preempted insofar as they exceed the scope of VARA (p. 462-463).

\section{Review of Literature}

There have been many conflicting perspectives regarding how moral rights legislation impacts the welfare of individual artists. Critics have been vocal in that, to establish a greater harmony between the artists' welfare, the United States, and the European Community, US law should be reformed to provide broader protections for moral rights (Hansmann, H., \& Santilli, M., 1997). While some suggest that economic analysis offers little insight into the impacts moral rights have on social welfare, some researchers have argued otherwise. Hansmann and Santilli (1997) argue that moral rights extend into both pecuniary and nonpecuniary benefits through the clause of integrity. In short, physical alteration, destruction, or mutilation of a particular work has the potential to harm an artist's reputation (p. 102106). This theory stems from the idea that an artist's body of work acts as an advertisement for the artist's other bodies of work, and destruction or mutilation to any singular work could disincentivize potential buyers (Sirota, 1992). In addition to that, Hansmann and Santilli (1997) argue that moral rights benefit the individual artist, other owners of the artist's work, and the public at large. They argue that an artist's spiritual connection and attachment to the integrity of

\footnotetext{
${ }^{2}$ The scope of VARA explicitly excludes some of the following in terms of visual art: posters, maps, globes, charts, technical drawings, diagrams, models, applied art, motion pictures and other audiovisual works, books, magazines, newspapers, periodicals, databases, electronic information services, electronic and similar publications, advertising, merchandising, promotional and packaging materials, and any works made for hire (Visual Artists Rights Act, 1990).

${ }^{3}$ VARA has no standard definition for "works of recognized stature." In court cases, a work can typically be determined to have recognized stature if that particular work is recognized in high regard by art experts, the artistic community, or society as a whole (Robinson, 2000).
} 
their body of work may supersede any expectations they have to prospective purchasers. A piece of work may also provide enriching social commentary or unique, appealing aesthetics, which could only be maintained through maintaining the artist's integrity (p. 102-106).

In an effort to empirically measure the impact of moral rights laws on artists' earnings, economist and professor William Landes (2001) employed a cross-sectional data analysis to argue that moral rights laws harm social welfare. Through this cross-sectional analysis, he found that data "suggests that larger, richer and better-educated states have relatively more artists and are more likely to enact moral rights laws" (p. 16). Landes also theorized that VARA may have a more significant adverse effect on site-specific works because they are more likely to be mutilated or destroyed after the transfer of economic rights from the artist to the buyer. As a result, prospective buyers of art may be incentivized to forego their purchases of site-specific works, weighing the preceding heavier than the added transactional costs of obtaining waivers or even violating the right to artists' integrity if they were to take the risk of purchasing the work (Landes, 2001).

Landes also presented findings that he proclaimed to be incongruous, asserting that his cross-sectional analysis suggests that, despite the fact that artists endure a slight economic disadvantage as a result of moral rights legislation, artists tend to reside in moral rights states as opposed to nonmoral rights states. He predicts that the laws tend to create a more advantageous social environment for artists as a possible explanation for this phenomenon (Landes, 2001). To estimate the impacts moral rights laws have on artist's economic welfare in moral and nonmoral rights states $^{4}$, researchers at Holy Cross University (2009) utilized a difference in differences framework to estimate how individual artist income is impacted as a result of moral rights legislation. Through this individual-level analysis, they concluded that artists living in moral rights states, compared to nonmoral rights states, lost up to $\$ 4250$ per year as a direct result of the legislation. Although these findings are able to confirm the theoretical predictions of Landes, in that the transaction costs associated with waiving moral rights act as a disincentive for buyers, they found that the laws had no impact on artists' choice of residence or state-level public spending on the arts. These findings disqualify the prediction that moral rights states tend to have a more favorable social climate that artists gravitate towards (Boyle et al. 2009).

Although the economic discrepancies between moral and nonmoral rights states have been compared through empirical methods of data analysis, there has yet to be a study comparing such between the various moral rights states. With Landes' findings that relatively more rich states tend to have more artists and enact statewide moral rights laws (Landes, 2001), the economies of these states have yet to be compared to each other. This is especially important when two factors are taken into consideration: (1) Chiefly, when considering the fact that the presence of moral rights laws does not seem to impact artists choice of residence, individuals in some states may be at a more significant inherent disadvantage than others, depending on which state they reside in. (2) There is cause to assume a discrepancy in economic prosperity between states, as the statewide GDP for moral rights states used in this study have a range of approximately 1468.05 billion dollars (Figure 3). Using GDP as a measure of the economic prosperity of a state (Bate, 2009), this paper explores the question: To what extent do changes in GDP between states with moral rights laws additional to VARA widen the income disparity between artists living in these states? I hypothesize that as statewide GDP increases, artists' losses resulting from moral rights legislation would also increase. Due to the fact that higher measures of GDP tend to have undoubtable ties to higher levels of urbanization (Chenery \& Taylor, 1968; Henderson 2003), I predict that these urban areas would have a higher proportion of site-specific works, of which would tend to be more likely subjects of moral rights legislation (Landes, 2001).

\footnotetext{
${ }^{4}$ This paper utilizes the term "moral and nonmoral rights states" in order to differentiate whether a state does, or does not, have additional statewide legislation. It is important to note that every US state is entitled to the rights under VARA.
} 


\section{Method}

In order to measure the extent to which the GDP of an individual moral rights state impacts artist's income, data from the US Bureau of Labor Statistics was collected and analyzed. After collecting the average incomes of artists and nonartists for each state, the incomes were substituted into a difference in differences framework, measuring the direct impact moral rights legislation has on artist income, a procedure directly mirrored off of the one utilized by researchers at Holy Cross University (Boyle et al. 2009). In order to measure the extent to which artists' income differs on the basis of statewide economic prosperity, the incomes were then correlated with GDP. The GDP of each state acted as the independent variable, while the average artist's income per state was the dependent variable.

As aforementioned, a difference in differences (DD) framework was utilized to measure the impact of moral rights legislation in each state. This framework is used as a statistical technique in econometrics to estimate the effects specific policies have on various variables, measuring the difference in the post-period of the treatment group against the same post-period in the control group, before and after a policy's enactment. In order to estimate causal effect using the DD framework, the following four assumptions must hold true: "Intervention [must be] unrelated to outcome at baseline, treatment/intervention, and control groups [must] have parallel trends in outcome, the position of intervention and comparison groups is stable for repeated cross-sectional design, and [there must be] no spillover effect." (Difference-in-Differences Estimation, n.d.).

The most pivotal assumption in this test is the parallel trends assumption. In this assumption, it is assumed that the control group will remain consistent in linear regression as the treatment group changes in the post-period, but not the pre-period. There is no statistical test that can be used to test the accuracy of control for this assumption (Difference-in-Differences Estimation, n.d.), but I attempted to control for it by strategically choosing the non-artist occupation of medical and health services managers. This career field's recession-resistant nature is vital to maintaining parallel linearity for the control group's pre and post-law periods, acting as a steady regulator for the changes in economic conditions over time (Weinstein \& Patrick, 2019).

Because the earliest pieces of statewide legislation were enacted in 1984, artist's and non-artists' weekly incomes were collected from 1983 for the pre-law period. The year 2019 was chosen for the post-law period to collect artist and non-artist incomes. This year was not only the most recent year that remained unaffected by the major extrinsic forces that resulted from the global COVID-19 pandemic taking place at the time of this study (Atkeson, 2020), but it was also readily available through the Occupational Employment and Wage Statistics (OES) data query, provided by the Bureau of Labor Statistics.

The states of Connecticut, Louisiana, Massachusetts, New Jersey, and New York were chosen to be tested in this study. These states were chosen because they all have additional, statewide moral rights laws that were enacted prior to the enactment of VARA. Other states that could have potentially been tested included California, Maine, Pennsylvania, New Mexico, Rhode Island, and Nevada. Despite all being moral rights states, a lack of data availability in the pre and post-law periods, as well as some having an enactment period before 1983, led to these states being excluded from the study; A lack of methodical adhesion to those facets would violate the critical components needed for the difference in differences framework that was employed. Although the states of Utah, Georgia, and Montana are also considered moral rights states, their state legislation offers minimal artists protection. This minimal protection led to their exclusion in previous studies, and so they will not be tested in this study as well (Boyle et al., 2009).

After collecting the results of the difference in difference formula for each state, I then paired each result of the estimating equation with the GDP of its respective state. Finally, to measure the extent, I employed a simple, linear regression T-Test to establish a correlation between each state through the line of best fit. 


\section{Data Collection and Analysis}

\begin{tabular}{cccc}
\multicolumn{2}{c}{ Artists } & Non-Artists \\
\hline $\begin{array}{c}\text { Pre-law }(A) \\
(1983)\end{array}$ & $\begin{array}{c}\text { Post-law }(B) \\
(2019)\end{array}$ & $\begin{array}{c}\text { Pre-law }(C) \\
(1983)\end{array}$ & $\begin{array}{c}\text { Post-law }(D) \\
(2019)\end{array}$
\end{tabular}

Connecticut

970.48

1807.69

1260.84

2480.19

Louisiana

(1986)

970.48

1490.96

1260.84

1965.57

Massachusetts

(1984)

970.48

931.54

1260.84

2556.92

New Jersey

(1986)

970.48

1363.65

1260.84

2320.19

New York (1984)

970.48

1872.31

1260.84

2826.92

Figure 1. Weekly Earnings: Artists and Non-Artists (2019 Dollars)

Note: All 1983 values (Mellor, 1983) have been adjusted for inflation using the BLS CPI Inflation Calculator, converting values from February 1983 to equivalent values for May 2019. All 2019 values were collected from the BLS data query (see Appendix A for artist values, and Appendix B for non-artist values). The values listed in parentheses directly underneath each state denote the year that each state's piece of moral rights legislation became effective.

Figure 1 shows artists' and non-artists weekly earnings prior to the implementation of any state legislation for all states listed for the pre-law period (1983) and the post-law period of the most recent and available census data (2019). The governmental process of obtaining statewide, occupational income data had not yet been established for the year 1983. In order to compensate for this limitation in data for both artists and non-artists during this pre-law period, the data utilized was taken from a February 1983 report by the Bureau of Labor Statistics listing weekly earnings by extensive occupational detail on a national scale. The data was not stratified to fit state characteristics, and so the assumption was made that each state adhered strictly to the national average in terms of occupational income. 


\section{Connecticut Louisiana Massachusetts New Jersey New York}

\begin{tabular}{cccccc}
\cline { 2 - 5 } $\begin{array}{c}\text { Treatment } \\
\text { Difference (B-A) }\end{array}$ & 837.21 & 520.48 & -38.94 & 393.12 & 901.83 \\
$\begin{array}{c}\text { Control Difference } \\
(\mathrm{D}-\mathrm{C})\end{array}$ & 1219.35 & 704.73 & 1296.08 & 1059.35 & 1566.08 \\
$\begin{array}{c}\text { Equation Estimate } \\
(\mathrm{DD})=(\mathrm{B}-\mathrm{A}) \text {-(D-C) }\end{array}$ & -382.14 & -184.25 & -1335.02 & 666.23 & -664.25 \\
\hline
\end{tabular}

Figure 2. Difference In Differences Estimate (2019 Dollars)

Note: The variables substitute for the equation estimate (DD) $=(B-A)-(D-C)$ are listed in Figure 1, defined as $(2019$ artists -1983 artists $)-(2019$ nonartists -1983 nonartists $)=$ impactoflaw $($ dollarsperweek $)$

Figure 2 shows the resulting estimates of the DD framework I employed, the final results being listed in row three, Equation Estimate. The difference in outcome for the treatment group is indicated using the variables (B-A), representing the difference between the weekly incomes of artists in 2019 and 1983, respectively. Similarly, the outcome for the control group is indicated using the variables (D-C), representing the difference between the weekly incomes of non-artists in 2019 and 1983, respectively. The Equation Estimate is the final result of the DD framework, each state showing losses as a result of the moral rights legislation.

\section{Louisiana Connecticut Massachusetts New Jersey New York}

\begin{tabular}{lccccc}
\cline { 2 - 6 } DD Estimate & -184.25 & -382.14 & $-1,335.02$ & -666.23 & -664.25 \\
$\begin{array}{l}\text { GDP (Billions } \\
\text { of Dollars) }\end{array}$ & 263.86 & 285.64 & 595.96 & 644.84 & 1731.91 \\
\hline
\end{tabular}

Figure 3. Difference In Differences Estimate Correlated with State GDP

Note: States are ordered from lowest GDP to highest from left to right respectively; DD estimates indicate weekly losses as a result of moral rights legislation; GDP data is measured in billions of US dollars for the year 2019. 


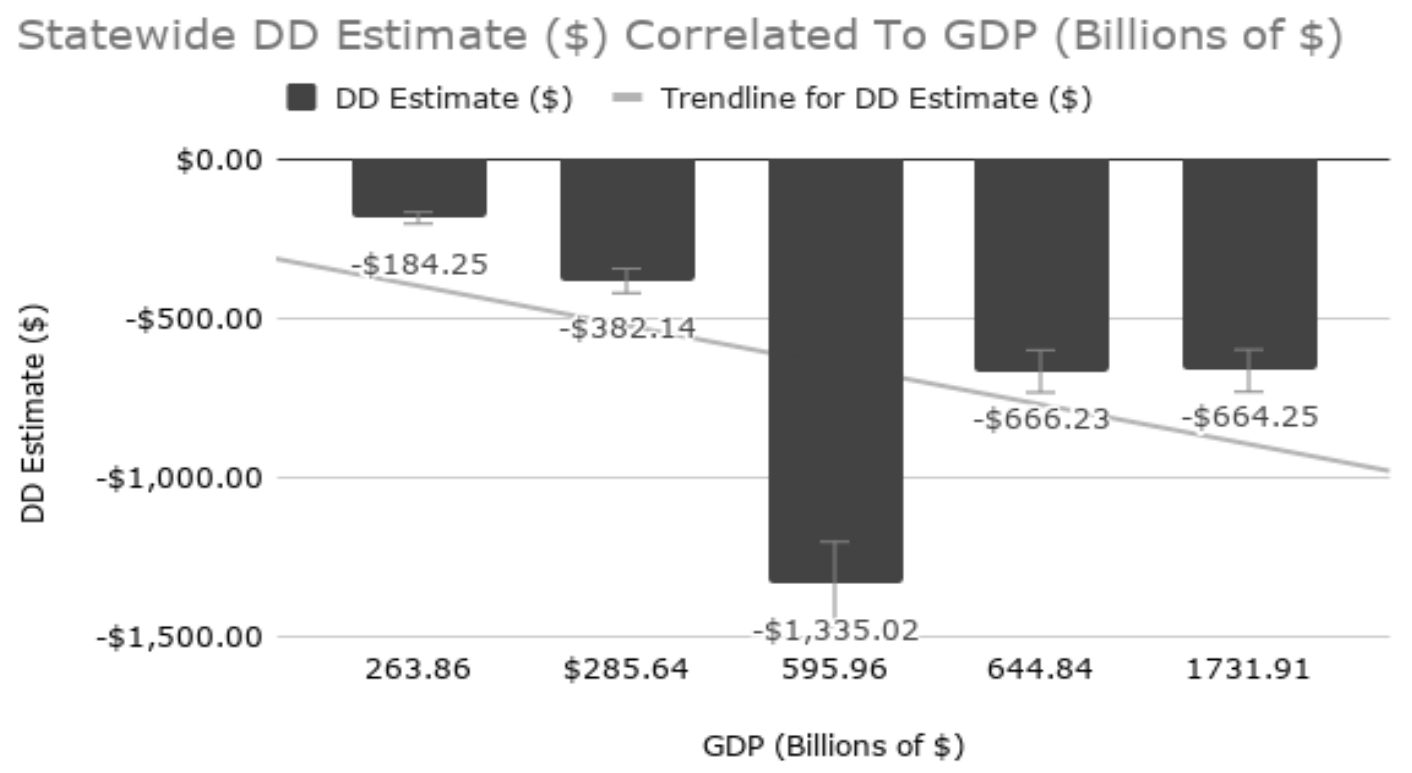

Figure 4. Difference In Differences Estimate Correlated with State GDP (Chart)

Figure 3 shows the resulting numeric values of the DD calculation correlated with each state's respective GDP value. The values can then be seen graphed in Figure 4. GDP acting as the independent variable along the x-axis, while the DD estimate acts as the dependent variable along the y-axis. According to the trendline, it is visually evident that as GDP increases positively, artists' weekly earnings tend to decrease. From this point, an additional statistical TTest was conducted to find the line of best fit for my data and measure the significance of the correlation, helping achieve a richer understanding of the relationship. The data yielded a statistically high p-value at 0.69 , indicating strong evidence in favor of the null hypothesis that there is no significant correlation between the variables. Even so, the line of best fit for my data was calculated at approximately -0.178 , meaning that if my data were considered to be statistically significant, artists would lose approximately $\$ 0.18$ per week as a result of statewide moral rights legislation, on average, per one billion dollar increase in GDP. My R-value shows a slight negative correlation, while my $\mathrm{R}$-Squared value shows that same correlation to be a poor fit for the data.

\section{Discussion}

The results of this study remain inconclusive. While it was found that artists' weekly losses amounted to approximately $\$ 0.18$ per one billion dollar increase in GDP between moral rights states, the statistical T-Test conducted showed these results to be insignificant. Thus, we fail to reject the null hypothesis, indicating no correlation between statewide artists' incomes and their respective GDP values.

It is important to note, however, that there are several formidable limitations to this study that should be considered when questioning my results. Due to a lack of available statewide occupational income data for the pre-law values, I had to make the primary assumption that each state adhered strictly to the national average in terms of artists and non-artist incomes when integrating these values into the DD framework. In actuality, geographic location can play a significant role in creating a wage gap for identical occupations operating in differing states (U.S. Bureau of Labor Statistics, n.d.). Consequently, in assuming strict adherence to a national average between each state I tested, I yielded results that were not true to life. In amending this study, future research should strive to control for this lack 
of data available through the utilization of various design-based models. Researchers at the US Census Bureau and the Bureau of Labor Statistics found several innovative methods to produce state-level estimates using national surveys (Ash et al., n.d.). In utilizing these methods, future researchers could apply various weights to the states that were tested, adjusting the income values using state-specific ratios that deal with state characteristics found in the OES data, such as employment, location quotient, etc (See Appendices A and B).

Limitations also exist within the DD method itself. The parallel trend assumption was the most critical assumption that needed to be fulfilled to ensure the validity of the DD method, and was difficult to verify because there is no statistical test for it (Difference-in-Differences Estimation, n.d.). Although I attempted to control for this through the strategic selection of a recession-proof industry for the control group, a lack of data points and an extensive period of time between data points may have negatively impacted the parallel trends in my treatment and control group (Difference-in-Differences Estimation, n.d.). This kind of instability within my data may have contributed to the lack of significance my results provided. In utilizing the DD framework for artists' and non-artists' incomes, future research should seek to add more years to, as well as narrow the span of time, for the pre and post-law periods, amending for this study's limitations.

While yielding inconclusive results, this study is still noteworthy through its identification of various limitations that may have caused statistical insignificance. The implications of a statistically significant study would be important to identifying the connection between artists' choice of residency and overall welfare. In disqualifying Landes' claim that moral rights laws have an impact on an artist's choice of residency (Boyle et al. 2009), it still remains uncertain whether some artists remain economically disadvantaged as a result of their choice of residency within a moral rights state. If this were to be the case, in order to establish greater economic equity, reformation to US moral rights laws should be advocated for on an economic basis. Greater economic equity for artists may relieve potential stressors within the population, allowing them to yield more aesthetically and socially enriching art, benefitting the population as a whole.

In investigating the impact of moral rights laws on the general welfare of both individuals and larger collective groups, there has yet to be a study completed analyzing the impact moral rights laws have on artistic innovation or creativity (Landes, 2001; Towse, 2006). This gap in research may exist because artistic innovation is an abstract concept that is difficult to measure concretely. In addition, although it has been observed that moral rights laws tend to exist in more affluent states, and that these affluent areas may have the tendency to have a more significant proportion of site-specific works due to the sizeable amount of urban landscape, there has yet to be a study conducted surveying the amount of site-specific works of visual art to urban areas. Because we know that site-specific works tend to be more heavily legislated regarding moral rights laws, creating a direct connection between the proportion of sitespecific works to urban areas may increase our understanding as to how the economies of these urban areas are impacted by artists who create these works, and vice versa. This additional research in the field would help provide a greater understanding of how states with various levels of urbanization are impacted by moral rights legislation. Future research is encouraged to explore these additional gaps and curiosities, adding to our overall understanding of the complex relationship between the economic and social impacts of moral rights laws.

\section{Acknowledgements}

I would like to thank Robert Hodgson, my research instructor and mentor, in motivating and supporting me through the research process through is feedback and passion for helping his students. Despite many hurdles and roadblocks along the way, he was always confident in the abilities of his students, truly setting us up for success. I would also like to thank the Millcreek Township School District for providing funding and support for the research process. 


\section{References}

Ash, S., Shaffer, B., \& Swanson, D. (n.d.). State-Level Design-Based Estimates for National Survey. https://www.census.gov/content/dam/Census/programs-surveys/ahs/working-papers/State-Level-Design-BasedEstimates-National.pdf.

Atkeson, A. (2020). What Will Be the Economic Impact of COVID-19 in the US? Rough Estimates of Disease Scenarios. https://doi.org/10.3386/w26867

Bate, R. (2009). What is Prosperity and How Do We Measure it? SSRN Electronic Journal. https://doi.org/10.2139/ssrn.2342844

Berne Convention, Article 6bis, (1971).

Boyle, M., Nazzaro, S., \& O'Connor, D. (2009). Moral rights protection for the visual arts. Journal of Cultural Economics, 34(1), 27-44. https://doi.org/10.1007/s10824-009-9113-3

Chenery HB, Taylor L (1968) Development patterns: among countries and over time. The Review of Economics and Statistics 50: 391-416.

Difference-in-Difference Estimation. Search the website. (n.d.). https://www.publichealth.columbia.edu/research/population-health-methods/difference-difference-estimation.

Hansmann, H., \& Santilli, M. (1997). Authors' and Artists' Moral Rights: A Comparative Legal and Economic Analysis. Economic Analysis of the Law, 100-110. https://doi.org/10.1002/9780470752135.ch10

Henderson V (2003) The urbanization process and economic growth: The so-what question. Journal of Economic Growth 8: 47-71.

Kewanee Oil Company v. Bicron Corporation 478 F.2d 1074 (1973).

Landes, W. M. (2001). What Has the Visual Arts Rights Act of 1990 Accomplished? SSRN Electronic Journal. https://doi.org/10.2139/ssrn.270985

Lerner, R. E., \& Bresler, J. (2006). In All about rights for visual artists (pp. 1-19). essay, Practising Law Institute.

Mellor, E., Earnings of Workers and Their Families. (1983). Weekly Earnings in 1983: a Look at More than 200 Occupations. https://www.bls.gov/opub/mlr/1985/01/rpt1full.pdf.

Thurston, Nataltia (2005) Buyer Beware The Unexpected Consequences of the Visual Artists Rights Act, 20 Berkeley Tech. L.J. 701

Robinson, Christopher (2000), The "Recognized Stature" Standard in the Visual Artists Rights Act, 68 Fordham L. Rev. 1935. Available at: https://ir.lawnet.fordham.edu/flr/vol68/iss5/15 
Sirota, Brett (1992) "The Visual Artists Rights Act: Federal Versus State Moral Rights," Hofstra Law Review: Vol. 21: Iss. 2, Article 4. Available at: http://scholarlycommons.law.hofstra.edu/hlr/vol21/iss2/4

Symposium, Authors, Attribution and Integrity: Examining Moral Rights in the United States," 8 Geo. Mason J. Int'1 Com L__ (2016) available at georgemasonjicl.org/wp-content/uploads/2016/08/Summer-Issue-2016.pdf

Towse, Ruth (2006). "Copyright and Creativity: An Application of Cultural Economics," Review of Economic Research on Copyright Issues. Vol. 3(2), 83-91.

U.S. Bureau of Labor Statistics. (n.d.). Same occupation, different pay: How wages vary: Career Outlook. U.S. Bureau of Labor Statistics. https://www.bls.gov/careeroutlook/2015/article/wage-differences.htm.

Visual Artists Rights Act of 1990, 17 U.S. Code § 106A. (1990).

Weinstein, A., \& Patrick, C. (2019). Recession-proof skills, cities, and resilience in economic downturns. Journal of Regional Science, 60(2), 348-373. https://doi.org/10.1111/jors.12446 